\title{
Analysis of the snow-atmosphere energy balance during wet-snow instabilities and implications for avalanche prediction
}

\author{
C. Mitterer and J. Schweizer \\ WSL Institute for Snow and Avalanche Research SLF, Davos Dorf, Switzerland \\ Correspondence to: C. Mitterer (mitterer@slf.ch) \\ Received: 14 June 2012 - Published in The Cryosphere Discuss.: 23 July 2012 \\ Revised: 7 December 2012 - Accepted: 28 December 2012 - Published: 1 February 2013
}

\begin{abstract}
Wet-snow avalanches are notoriously difficult to predict; their formation mechanism is poorly understood since in situ measurements representing the thermal and mechanical evolution are difficult to perform. Instead, air temperature is commonly used as a predictor variable for days with high wet-snow avalanche danger - often with limited success. As melt water is a major driver of wet-snow instability and snow melt depends on the energy input into the snow cover, we computed the energy balance for predicting periods with high wet-snow avalanche activity. The energy balance was partly measured and partly modelled for virtual slopes at different elevations for the aspects south and north using the 1-D snow cover model SNOWPACK. We used measured meteorological variables and computed energy balance and its components to compare wet-snow avalanche days to non-avalanche days for four consecutive winter seasons in the surroundings of Davos, Switzerland. Air temperature, the net shortwave radiation and the energy input integrated over 3 or 5 days showed best results in discriminating event from non-event days. Multivariate statistics, however, revealed that for better predicting avalanche days, information on the cold content of the snowpack is necessary. Wet-snow avalanche activity was closely related to periods when large parts of the snowpack reached an isothermal state $\left(0^{\circ} \mathrm{C}\right)$ and energy input exceeded a maximum value of $200 \mathrm{~kJ} \mathrm{~m}^{-2}$ in one day, or the 3-day sum of positive energy input was larger than $1.2 \mathrm{MJ} \mathrm{m}^{-2}$. Prediction accuracy with measured meteorological variables was as good as with computed energy balance parameters, but simulated energy balance variables accounted better for different aspects, slopes and elevations than meteorological data.
\end{abstract}

\section{Introduction}

Wet-snow avalanches are difficult to forecast, but often threaten communication lines in snow-covered mountain areas. Once the snowpack becomes wet the release probability obviously increases, but determining the peak and end of a period of high wet-snow avalanche activity is particularly difficult (Techel and Pielmeier, 2009).

Processes leading to wet-snow avalanches are complex and the conditions of the snowpack may change from stable to unstable in the range of hours (Trautman, 2008). The presence of liquid water within the snowpack in the starting zone is a prerequisite and several field campaigns (Brun and Rey, 1987; Bhutiyani, 1996) and experiments under laboratory conditions (Zwimpfer, 2011; Yamanoi and Endo, 2002) found decreasing shear strength with increasing liquid water content. However, quantifying the amount of liquid water within the snowpack is a difficult task as even experienced observers tend to overestimate the amount of liquid water (Fierz and Föhn, 1995; Techel and Pielmeier, 2011). Only objective measurement devices relating the relative permittivity of the 3-phase medium wet snow to an amount of water provide reliable results. Most devices though are for research purposes only and until today the operational use is hindered by practical and financial constraints. In addition, no established procedure exists to assess wet-snow instability. In situ stability tests commonly used to assess dry-snow instability showed ambiguous results when performed in moist or wetsnow covers (Techel and Pielmeier, 2010).

Given the poor understanding of the formation mechanism and the lack of indicative measurements, statistical rather than physical modelling has been used to predict wet-snow instability. While for large new snow avalanches the 3-day 
sum of precipitation is the strongest forecasting parameter (Schweizer et al., 2009) and closely related to avalanche danger (Schweizer et al., 2003a), air temperature is often used as a critical parameter for predicting wet-snow avalanche activity (McClung and Schaerer, 2006). It is included in statistical prediction tools that were designed for a specific area (e.g. Romig et al., 2005). However, there are many examples which show that air temperature is in many cases not a good predictor and causes a high number of false alarms (Kattelmann, 1985). Nevertheless, it appears to be a variable clearly related to wet-snow instability (Baggi and Schweizer, 2009; Peitzsch et al., 2012).

To clarify the meteorological boundary conditions favouring the triggering of wet-snow avalanches, we analyzed four winter seasons (from 2007-2008 to 2010-2011) with different distinct wet-snow avalanche events in the surroundings of Davos, Switzerland. As suggested by Trautman (2008), we computed the entire energy balance for the snowpack with special attention to the main sources for snow melt, namely the incoming longwave and shortwave radiation and the sensible heat flux (Ohmura, 2001). We used univariate and multivariate statistics to evaluate whether these three sources were relevant shortly before and during the instabilities. In addition, we analyzed meteorological parameters of nearby stations and evaluated whether the predictive power of the energy balance and its terms performed better than widely used meteorological parameters such as air temperature.

\section{Data}

\subsection{Avalanche occurrence}

Avalanche occurrence data were recorded for the winters 2007-2008 to 2010-2011 for the surroundings of Davos, Switzerland. Data consisted of avalanche size (Canadian avalanche size class, McClung and Schaerer, 2006) and included only events which were classified as wet-snow avalanches. The classification into wet or dry is based on observation, mainly on visual clues. No measurements on the amount of liquid water within the starting zones were available but most observers are well trained to discriminate between wet and dry-snow avalanches. We included both, wet-loose avalanches and wet-slab avalanches in our avalanche days. Considering all avalanche cycles, about as many loose-snow avalanches as slab avalanches were reported (104 vs. 77). With regard to the location of the failure surface, $42 \%$ released within the snowpack and $58 \%$ of the avalanches at the snow-soil interface. We calculated a daily avalanche activity index (AAI) using a weighted sum of recorded avalanches per day with weights of 0.01, 0.1, 1 and 10 for size classes 1 to 4 , respectively (Schweizer et al., 2003b). In order to exclude days with either many small avalanches or with a single large event, only days with an AAI $>2$ were considered as wet-snow avalanche days for the
Table 1. Major wet-snow avalanche cycles (i.e. AAI > 30) in the surroundings of Davos, Switzerland, for the winters 2007-2008 to 2010-2011. Aspect index was calculated by relating the number and size of avalanches released on slopes of northern to those on southern aspects. Only for the cycle on 23 April 2008 no clear aspect could be assigned. Days with low activity are not included in the Table.

\begin{tabular}{lllrr}
\hline Winter & Date & $\begin{array}{l}\text { Aspect } \\
\text { index }\end{array}$ & $\begin{array}{r}\text { Avalanche } \\
\text { activity index } \\
\text { (per day) }\end{array}$ & $\begin{array}{r}\text { Median elevation } \\
\text { of starting zones } \\
\text { (m a.s.1.) }\end{array}$ \\
\hline \multirow{2}{*}{$2007-2008$} & $19 \mathrm{Apr}$ & South & 35 & 2400 \\
& $23 \mathrm{Apr}$ & South/North & 164 & 2250 \\
$2008-2009$ & $18 \mathrm{Mar}$ & South & 32 & 2075 \\
& $1 \mathrm{Apr}$ & South & 85 & 2200 \\
& $2 \mathrm{Apr}$ & South & 45 & 2200 \\
& $3 \mathrm{Apr}$ & South & 58 & 2200 \\
& $6 \mathrm{Apr}$ & South & 31 & 2200 \\
$2009-2010$ & $21 \mathrm{Mar}$ & South & 115 & 2200 \\
& $22 \mathrm{Mar}$ & South & 60 & 2200 \\
& $23 \mathrm{Mar}$ & South & 31 & 2200 \\
$2010-2011$ & $1 \mathrm{Apr}$ & South & 32 & 2400 \\
& $2 \mathrm{Apr}$ & North & 47 & 2400 \\
& $8 \mathrm{Apr}$ & North & 55 & 2300 \\
\hline
\end{tabular}

statistical analyses (see below). In addition, we calculated the median elevation of the release zones. Due to the recording system used in Switzerland it was not possible to relate single events and their size to a given aspect as one record may contain multiple events - still the dominating aspects are reported. Therefore, we introduced an aspect index, which is the ratio of the frequency and size of avalanches recorded in southern aspects to the one recorded in northern aspects. If the ratio was $>1$ we assumed that the avalanche cycle mainly occurred in southern aspects and vice versa for $<1$. Following this approach, we obtained 66 wet-snow avalanche days and 663 non-avalanche days for the four winters. The major avalanche cycles with date, aspect index and elevation of release zones are given in Table 1.

\subsection{Meteorological data}

Meteorological data were obtained from three automatic weather stations: Weissfluhjoch (WFJ, $2540 \mathrm{~m}$ a.s.l.), Stillberg (STB, $2150 \mathrm{~m}$ ) and Dorfberg (DFB, $2140 \mathrm{~m}$ ). After the first winter season 2007-2008 data from STB were replaced by data from the new Dorfberg weather station, which is located in the vicinity of a well-known wet-snow avalanche starting zone. The three stations are located at two distinct elevations: STB and DFB are slightly above the tree-line, near the lower limit of where most wet-slab avalanches are initiated, and WFJ is located higher than most starting zones of all wet-snow avalanche cycles.

For the statistical analyses, radiation (all four components), snow depth, relative humidity and air temperature were used as explanatory variables. In addition to mean, maximum and minimum values, we derived differences and sums over 1, 3 and 5 days; wind was not considered. 


\subsection{Simulations with SNOWPACK}

In order to obtain energy balance data for slopes of various elevations and aspects we used the 1-D snow cover model SNOWPACK (Lehning et al., 2002a, b; Lehning and Fierz, 2008). Slope angle was fixed to $35^{\circ}$ which represents the median slope angle of all recorded wet-snow avalanche releases. Input data for the model were meteorological values taken only from the weather station Weissfluhjoch (WFJ); we had to extrapolate or adapt air temperature, snow surface temperature and incoming shortwave radiation for different elevations and aspects. Air temperature was extrapolated using a constant lapse rate of $0.65^{\circ} \mathrm{C} / 100 \mathrm{~m}$. Outgoing longwave radiation and consequently snow surface temperature was modelled in SNOWPACK using Neumann boundary conditions (Lehning et al., 2002b). We adapted the input of the shortwave radiation according to the lapse rate suggested by Marty (2001) which is a lapse rate based on measurements at different elevations. We did simulations only for slopes of the two main aspects, i.e. $0^{\circ}(\mathrm{N})$ and $180^{\circ}(\mathrm{S})$. The change in incoming solar radiation on these aspects was taken into account. In brief, to run the model, we used air temperature, relative humidity, incoming shortwave, incoming longwave, reflected shortwave radiation, wind direction, wind speed, and snow depth. Components of the radiation balance and air temperature including relative humidity were measured under ventilated conditions. Simulations were performed for 2000, 2200 and $2500 \mathrm{~m}$ a.s.l. For slope simulations, snow depth was modelled with a precipitation mass input and albedo was determined as a function of grain type, grain size and presence of liquid water at the snow surface. Again daily means, maximum, minimum and 1, 3 and 5 day sums were derived from the energy balance terms.

\section{Methods}

\subsection{Calculation of energy balance and liquid water}

The energy balance was calculated using SNOWPACK. Within the model the energy balance can be calculated in two different ways. The first mode calculates the net change rate $\mathrm{d} H / \mathrm{d} t$ of the snowpack's internal energy per unit area as the sum of all energy fluxes at the surface:

$$
-\frac{\mathrm{d} H}{\mathrm{~d} t}=S^{\downarrow}+S^{\uparrow}+L^{\downarrow}+L^{\uparrow}+H_{\mathrm{S}}+H_{\mathrm{L}}+H_{\mathrm{P}}+G,
$$

where $S^{\downarrow}$ and $S^{\uparrow}$ are the downward and reflected components of shortwave radiation, respectively, $L^{\downarrow}$ and $L^{\uparrow}$ are the downward and upward components of longwave radiation, respectively, $H_{\mathrm{S}}$ and $H_{\mathrm{L}}$ are the turbulent fluxes of sensible and latent heat through the atmosphere, $H_{\mathrm{P}}$ is the flux of energy carried as sensible or latent heat by both precipitation and blowing snow, and $G$ is the ground heat flux (King et al., 2008).
For our analyses $S^{\downarrow}, S^{\uparrow}, L^{\downarrow}$ and $L^{\uparrow}$ were measured, $H_{\mathrm{S}}$, $H_{\mathrm{L}}$ and $H_{\mathrm{P}}$ modelled, and $G$ fixed to a constant value. The sensible heat $H_{\mathrm{S}}$ (Eq. 2) and the latent heat flux $H_{\mathrm{L}}$ (Eq. 4) were calculated assuming a neutral atmospheric surface layer and using Monin-Obukhov similarity theory resulting in:

$H_{\mathrm{S}}(0)=-C \rho_{\mathrm{a}} c_{\mathrm{p}}(T(z)-T(0))$,

where $T(z)$ is the air temperature at height $z, T(0)$ the snow surface temperature, $\rho_{\mathrm{a}}$ the density of air and $c_{\mathrm{p}}$ the heat capacity; the kinematic transfer coefficient $C$ is given according to

$$
C=\frac{-k u_{*}}{0.74 \ln \frac{z}{z_{0}}},
$$

where $k$ is the von Karman constant, $u_{*}$ is the friction velocity of the wind and $z$ the height of the wind measurement. The latent heat is defined as

$$
H_{\mathrm{L}}=-C \frac{0.622 L^{\mathrm{w} / \mathrm{i}}}{R_{\mathrm{a}} T(z)}\left[e_{\mathrm{s}}^{\mathrm{w}}(T(z)) \mathrm{RH}-e_{\mathrm{s}}^{\mathrm{i}}(T(0))\right],
$$

where $R_{\mathrm{a}}$ is the gas constant for dry air, $L^{\mathrm{w} / \mathrm{i}}$ are the latent heat values for vaporization and sublimation, respectively, $e_{\mathrm{s}}^{\mathrm{w} / \mathrm{i}}$ is the saturation vapour pressure over water or ice, and RH the relative humidity.

Assuming neutral stability conditions are valid during periods with moderate to high wind speeds which often prevail in complex mountainous terrain (Lehning et al., 2002a), Stössel et al. (2010) showed that outgoing longwave radiation is better accounted for within SNOWPACK when forcing neutral conditions.

The second mode for the energy balance in SNOWPACK involves calculating the internal change of energy based on either warming and melting, or cooling and freezing; it is given by:

$$
-\frac{\mathrm{d} H}{\mathrm{~d} t}=L_{\mathrm{li}}\left(R_{\mathrm{F}}-R_{\mathrm{M}}\right)-\int_{0}^{\mathrm{HS}}\left[\frac{\mathrm{d}}{\mathrm{d} t}\left(\rho_{\mathrm{s}}(z) c_{\mathrm{p}, \mathrm{i}} T_{\mathrm{S}}(z)\right)\right] \mathrm{d} z,
$$

where $R_{\mathrm{F}}$ and $R_{\mathrm{M}}$ are the freezing and melting rate, respectively, $L_{\mathrm{li}}$ the latent heat of fusion of ice, and $c_{\mathrm{p}, \mathrm{i}}$ the specific heat capacity of ice; $\rho_{\mathrm{S}}$ is the snow density and $T_{\mathrm{S}}$ is the snow temperature, both at height $z$ (King et al., 2008). The second mode also allows for calculating the cold content of the snowpack, which is the second term of the RHS in Eq. (5). The cold content describes how much energy is needed to warm the snow to $0^{\circ} \mathrm{C}$. In this way it was possible to model whether the energy input resulting from the energy flux at the surface is used for warming or already for melting snow. A snowpack, where at every height $z$ the cold content equals $0 \mathrm{~kJ} \mathrm{~m}^{-2}$, is equivalent to an isothermal snowpack. We calculated the proportion of the snowpack reaching this state and refer to it as proportion zero cold content. 
SNOWPACK contains parameterisations of water percolation, retention and refreezing processes and calculates the liquid water content for single layers. There are two possibilities to calculate the liquid water content for every layer within the modelled snow cover (Hirashima et al., 2010). Since water transport, especially on slopes is a very complex phenomenon, the water transport codes that are presently implemented within SNOWPACK cannot depict the full complexity of flowing water within the snowpack which is responsible for wet-snow avalanche formation. Both approaches have benefits, but compared to observations substantial deviations were found (Mitterer et al., 2011). Therefore, we did not use liquid water values calculated for single layers with one of the two schemes in the statistical analyses. Instead we used the total amount of liquid water within the snowpack. This value is directly linked to the energy balance and the cold content of snow and gives an estimate of how much water was present during the days with wet-snow avalanche activity.

\section{Statistical analyses}

The non-parametric Mann-Whitney $U$-test (Spiegel and Stephens, 1999) was used to contrast meteorological or energy flux variables from avalanche and non-avalanche days. Observed differences were judged to be statistically significant where the level of significance was $p<0.05$, i.e. the null hypothesis that the two groups are from the same population was rejected. In order to obtain a balanced data set of avalanche and non-avalanche days, we randomly selected the same number of non-avalanche days considering the frequency of wet-snow avalanche days per month for the period December-May. Non-avalanche days were selected 10 times and for every run a $p$-value was computed. We averaged the $p$-values and only if the $U$-test indicated a statistically significant difference, variables were passed to a classification tree analysis (Breiman et al., 1998) and its newer derivative the RandomForest classification (Breiman, 2001). Classification trees were obtained by optimising the misclassification costs and the complexity (size) of a tree. Tree size was determined through cross-validation (10-fold). To minimise the effect of randomly selecting non-avalanche days, we performed the tree analysis 20 times and selected the tree combination which showed up in most of the cases (in our case about 2/3).

RandomForest (RF) is a newer derivative of the classification tree analysis. We used the package RandomForest (Version 4.6-2) incorporated in the R-project. The code is based on the work of Breiman (2001). It uses bootstrap samples to construct multiple trees. Each tree is grown with a randomised subset of predictors that allows the trees to grow to their maximum size without pruning. Finally the results of all trees are aggregated by averaging the trees. Out-of-bag samples are used to calculate an unbiased error rate and variable
Table 2. Contingency table (total cases: $N=a+b+c+d$ )

\begin{tabular}{llll}
\hline & \multicolumn{2}{c}{ Observed } \\
\cline { 3 - 4 } & & Non-avalanche day & Avalanche day \\
\hline \multirow{2}{*}{ Model } & Non-avalanche day & $a$ : correct non-event & $b$ : missed event \\
& Avalanche day & $c$ : false alarm & $d:$ correct event \\
\hline
\end{tabular}

importance, without the need for a training data set or cross validation. Variable importance is based on how much worse the prediction would be if the data for that predictor were permuted randomly. The stronger the decrease in prediction accuracy, the more important is the variable (Breiman, 2001). As this importance measure is calculated for each node, a more local importance is given. For our data set we produced $N=500$ trees and restricted the randomised subset of predictors to a minimum of 7 , but a maximum of $\sqrt{n}$, where $n$ is the number of predictors passed from the results of the $U$-test. To assess the performance of the multivariate analysis (classification tree and RandomForest) we used the true skill score (HK), the false alarm ratio (FAR), the probabilities of detection of events (POD), and non-events (PON). With definitions used in contingency tables (Table 2) the measures are defined as follows (Wilks, 1995; Doswell et al., 1990):

Probability of detection: $\mathrm{POD}=\frac{d}{b+d}$

Probability of non-events: $\mathrm{PON}=\frac{a}{a+c}$

False alarm ratio $\mathrm{FAR}=\frac{c}{c+d}$

True skill score $\mathrm{HK}=\frac{d}{b+d}-\frac{c}{a+c}$

The true skill score, also called the Hanssen and Kuipers discriminant, is a measure of the forecast success and accounts for the correct discrimination of events and nonevents. Of course, false-stable predictions can have more serious consequences than false alarms, but too many false alarms will not provide meaningful insight into the meteorological boundary conditions prevailing during wet-snow instabilities as we cannot define patterns which are common for unstable wet-snow situations.

\section{Results}

We first report on the univariate analysis of the data including the meteorological parameters (Table 3) and those obtained by calculating the energy balance (Table 4, Fig. 1). Then we present the results obtained with the multivariate 
Table 3. Comparison of avalanche (AvD) to non-avalanche days (nAvD) for meteorological data measured at the weather stations Weissfluhjoch (2540 m a.s.1) and Dorfberg (2140 m a.s.1.). Median values are shown; Dorfberg values for the season 2007-2008 are substituted with values from Stillberg (2150 m a.s.l.). For each variable, distributions from avalanche days and non-avalanche days were contrasted $(U$-test), and the level of significance ( $p$-value) is given. Only variables with $p<0.05$ are shown.

\begin{tabular}{|c|c|c|c|c|c|c|}
\hline \multirow[t]{3}{*}{ Variable } & \multicolumn{3}{|c|}{ Weissfluhjoch (WFJ) } & \multicolumn{3}{|c|}{ Dorfberg (DFB) } \\
\hline & \multicolumn{2}{|c|}{ Median } & \multirow[t]{2}{*}{$p$-value } & \multicolumn{2}{|c|}{ Median } & \multirow[t]{2}{*}{$p$-value } \\
\hline & AvD & $\mathrm{nAvD}$ & & $\mathrm{AvD}$ & nAvD & \\
\hline $\mathrm{TA}_{\text {mean }}\left({ }^{\circ} \mathrm{C}\right)$ & -0.4 & -4.1 & $<0.01$ & 3.7 & 2.6 & $<0.01$ \\
\hline $\mathrm{TA}_{\min }\left({ }^{\circ} \mathrm{C}\right)$ & -2.3 & -6.7 & $<0.01$ & 0.5 & -6.3 & $<0.01$ \\
\hline $\mathrm{TA}_{\max }\left({ }^{\circ} \mathrm{C}\right)$ & 2.1 & -1.5 & $<0.01$ & 5.1 & -0.7 & $<0.01$ \\
\hline$\Delta \mathrm{TA} 3 \mathrm{~d}\left({ }^{\circ} \mathrm{C}\right)$ & 1.2 & -0.1 & 0.01 & 1.2 & 0.1 & 0.42 \\
\hline$\Sigma 3 \mathrm{~d}$ TA positive $\left({ }^{\circ} \mathrm{C}\right)$ & 65 & 4 & $<0.01$ & 357 & 12 & $<0.01$ \\
\hline$\Sigma 5$ d TA positive $\left({ }^{\circ} \mathrm{C}\right)$ & 97.3 & 15.7 & 0.01 & 520 & 54 & 0.01 \\
\hline$\Delta \mathrm{HS} 3 \mathrm{~d}(\mathrm{~cm})$ & -6 & 0 & 0.03 & -1.5 & 0 & 0.36 \\
\hline $\mathrm{TSS}_{\text {mean }}\left({ }^{\circ} \mathrm{C}\right)$ & -4.2 & -6.5 & 0.01 & 0 & -4.2 & 0.04 \\
\hline $\mathrm{TSS}_{\min }\left({ }^{\circ} \mathrm{C}\right)$ & -10.5 & -13.2 & 0.04 & -2.2 & -11.6 & $<0.01$ \\
\hline $\mathrm{TSS}_{\max }\left({ }^{\circ} \mathrm{C}\right)$ & 0 & -1.6 & $<0.01$ & 0 & 0 & 0.19 \\
\hline $\mathrm{RH}_{\text {mean }}(\%)$ & 69 & 78 & 0.09 & 72 & 69 & 0.03 \\
\hline Min radiation balance $\left(\mathrm{Wm}^{-2}\right)$ & -77 & -71 & 0.02 & -72 & -70 & 0.26 \\
\hline Max radiation balance $\left(\mathrm{Wm}^{-2}\right)$ & 110 & 69 & 0.04 & 501 & 241 & 0.26 \\
\hline$\Sigma 5 \mathrm{~d}$ positive radiation balance $\left(\mathrm{Wm}^{-2}\right)$ & 3907 & 3354 & 0.7 & 17847 & 12582 & 0.49 \\
\hline Mean incoming shortwave $\left(\mathrm{Wm}^{-2}\right)$ & 227 & 204 & 0.02 & 215 & 173 & 0.2 \\
\hline Mean outgoing longwave $\left(\mathrm{Wm}^{-2}\right)$ & 301 & 291 & 0.02 & 315 & 297 & 0.03 \\
\hline Min outgoing longwave $\left(\mathrm{Wm}^{-2}\right)$ & 277 & 266 & 0.03 & 305 & 268 & $<0.01$ \\
\hline Max outgoing longwave $\left(\mathrm{Wm}^{-2}\right)$ & 312 & 304 & $<0.01$ & NA & NA & - \\
\hline
\end{tabular}
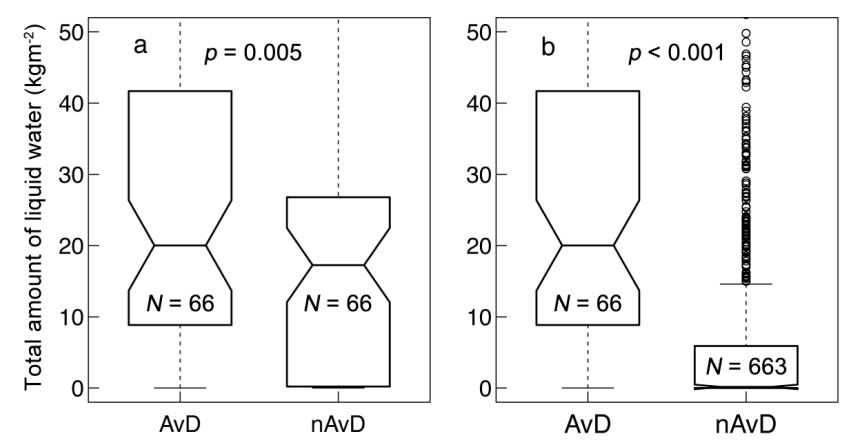

Fig. 1. Contrasting avalanche days (AvD) to non-avalanche days (nAvD) for the daily maximum amount of liquid water within the snowpack for (a) a subset of non-avalanche days and (b) all nonevent days within the data set with data obtained from a simulation representing a south-facing slope. Boxes span the interquartile range, whiskers extend to 1.5 times the interquartile range. Outliers are shown with open circles. Notches are defined by \pm 1.5 times the interquartile range divided by the square root of $\mathrm{N}$.

approaches, i.e. classification trees (Figs. 2 and 4) and RandomForest (Fig. 3), and compare the predictive power of the models created with either meteorological measurements or energy balance variables.

\subsection{Univariate analysis}

For the meteorological variables minimum, mean, maximum, and the positive sum of air temperature over 3 days, the distributions were statistically different with $p<0.01$ for the two classes of wet-snow avalanche day/non-avalanche day (Table 3). Therefore, these variables were significant indicators for a day with an AAI > 2. Furthermore, the distributions for the minimum snow surface temperature $\left(T_{\mathrm{SS}}\right)$ were significantly different between the two classes for all stations. The mean and maximum of $T_{\mathrm{SS}}$, the difference of air temperature in the last $24 \mathrm{~h}$ and the difference in snow height for $24 \mathrm{~h}$ or 3 days discriminated between the groups only with the data of WFJ. Not surprisingly, days with an AAI $>2$ had always higher air and snow surface temperatures and a preceding period ( 3 or 5 days) with higher air temperatures than nonavalanche days. Also significant differences between the two groups of days were found for some variables derived from the radiation balance measured at the stations. Avalanche days received more energy input through radiation than nonavalanche days, though distributions were not always significantly different; outgoing longwave radiation $\left(L^{\uparrow}\right)$ showed always high values for avalanche days. In other words, $T_{\mathrm{SS}}$ was always higher on avalanche days than on non-avalanche days. 


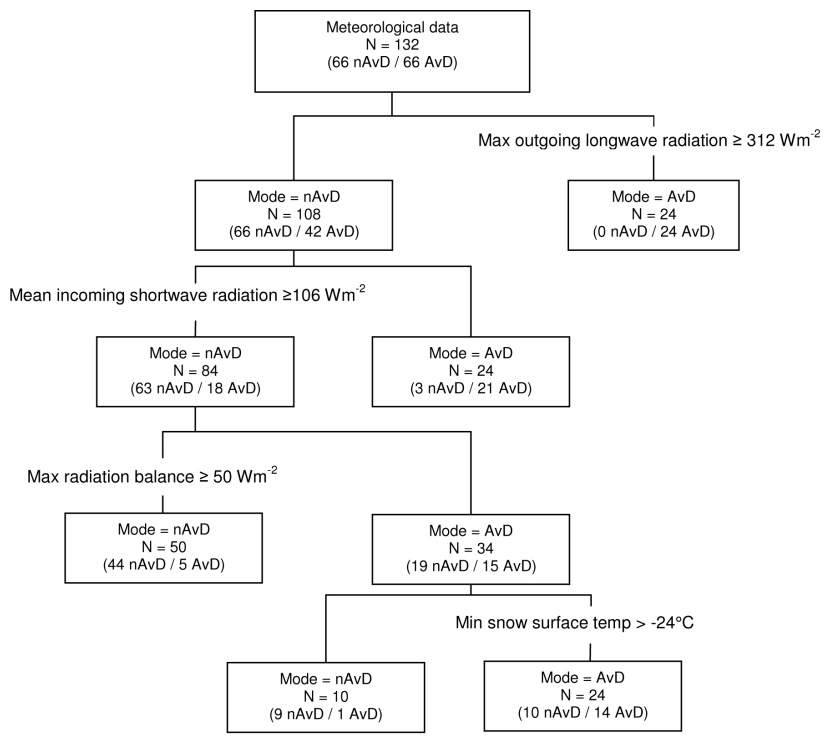

Fig. 2. Classification tree to discriminate between avalanche $(\mathrm{AAI}>2)$ and non-avalanche days. Input data were all meteorological variables taken from WFJ, if $U$-test was significant. Forecast scores of the tree: probability of detection $(\mathrm{POD})=0.89$; probability of non-events $(\mathrm{PON})=0.8$; true skill score $(\mathrm{HK})=0.69$.

The daily minimum of sensible heat $\left(H_{\mathrm{S}}\right)$, the mean net longwave, the minimum, mean, maximum value of $L^{\uparrow}$, all sums of $L^{\uparrow}$ and the 3-day sum of positive energy balance were the only variables for which the differences were judged significant for both aspects (Table 4). All other variables appear only in one of the two aspect classes. For the simulations on south-facing slopes all variables dealing with net and incoming shortwave radiation $\left(S^{\downarrow}\right)$ discriminated well between avalanche and non-event days. Daily minimum and maximum values of the energy balance performed well in distinguishing between avalanche and non-avalanche days for southern slopes only. On wet-snow avalanche days on southfacing slopes, the energy input into the snowpack was higher due to high net shortwave radiation and higher net longwave radiation than on non-avalanche days. Avalanche days on north-facing slopes were characterised by a high minimum value of $H_{\mathrm{S}}$ and long periods ( 3 days) of energy input. $L^{\uparrow}$ was always higher on avalanche days than on non-avalanche days.

The maximum value for the total amount of liquid water within the snowpack discriminated well between avalanche and non-avalanche days, but only for southern aspects (Fig. 1a). The difference becomes even more evident when including all available non-avalanche days (Fig. 1b). The interquartile ranges of the two distributions do not overlap at all, however, a considerable number of outliers represent days with a high amount of liquid water, but no avalanche activity. For north-facing slopes the two distributions were similar (Table 4).
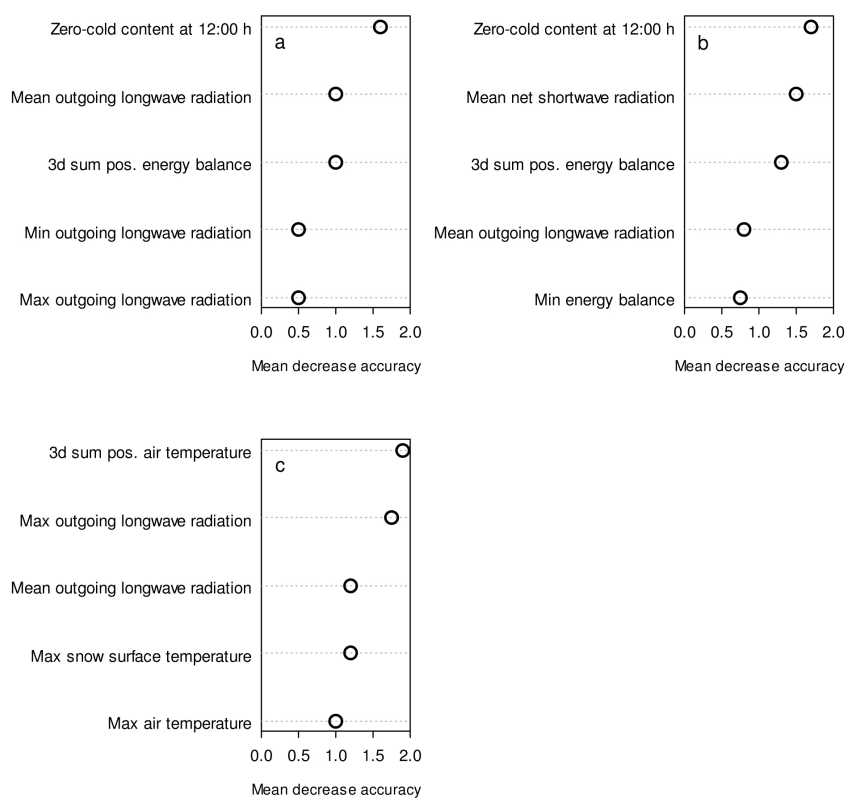

Fig. 3. The five most important variables for RandomForest models built with data obtained from (a) simulated north-facing slopes $\left(2500 \mathrm{~m}, 35^{\circ}\right)$, (b) simulated south-facing slopes $\left(2500 \mathrm{~m}, 35^{\circ}\right)$, and (c) meteorological parameters recorded at the station Weissfluhjoch to classify wet-snow avalanche and non-avalanche days. Variable importance is based on how much worse the prediction would be if the data for that predictor were permuted randomly; the stronger the decrease in accuracy, the higher is the variable importance.

\subsection{Multivariate analysis}

For the multivariate approaches we pre-selected the variables based on Table 3 and Table 4 according to their physical meaningfulness and significance in the univariate approach. Again, the same quantity of non-avalanche days $(N=66)$ was selected according to the frequency of avalanche days ( $N=66)$ for the months December to May.

The classification tree with the meteorological parameters of WFJ used only terms of the radiation balance to split into the two classes. Air temperature was not chosen by the tree (Fig. 2). Avalanche days were detected with almost $90 \%$ accuracy when following the nodes of the tree; non-event days were identified with a probability of $80 \%$. False-stable predictions were less frequent than false alarms. The RandomForest (RF) model with the WFJ data not only included different radiation terms, but also the 3-day sum of positive air temperature and the maximum air temperature into the topfive important variables (Fig. 3c). Predictive performance of the RF statistical model was 10-20\% worse than the one of the classification tree. POD and PON decreased to $69 \%$, concurrently FAR increased to $34 \%$. In the tree compiled with the DFB data set (not shown here), the sum of air temperature over $24 \mathrm{~h}$ and the values of relative humidity were the dominant splitting parameters. The RF could not be applied to 
Table 4. Comparison of avalanche (AvD) to non-avalanche days (nAvD) for variables derived from the energy balance calculated for a $35^{\circ}$ slope. For each variable, distributions from avalanche days and non-avalanche days are contrasted ( $U$-test), and the level of significance ( $p$-value) is given. Only variables with $p<0.05$ are shown.

\begin{tabular}{|c|c|c|c|c|c|c|}
\hline \multirow[t]{2}{*}{ Variable } & \multicolumn{2}{|c|}{ Median for $2500 \mathrm{~m}$, South } & \multirow[t]{2}{*}{$p$-value } & \multicolumn{2}{|c|}{ Median for $2500 \mathrm{~m}$, North } & \multirow[t]{2}{*}{$p$-value } \\
\hline & AvD & $\mathrm{nAvD}$ & & $\mathrm{AvD}$ & $\mathrm{nAvD}$ & \\
\hline Min sensible heat $\left(\mathrm{Wm}^{-2}\right)$ & -5 & -20 & $<0.01$ & 3 & -2 & 0.04 \\
\hline Mean net longwave $\left(\mathrm{Wm}^{-2}\right)$ & -51 & -35 & 0.02 & -42 & -31 & 0.02 \\
\hline Mean outgoing longwave $\left(\mathrm{Wm}^{-2}\right)$ & 302 & 293 & $<0.01$ & 292 & 284 & 0.03 \\
\hline Min outgoing longwave $\left(\mathrm{Wm}^{-2}\right)$ & 277 & 0.03 & 270 & 261 & 0.04 & \\
\hline Max outgoing longwave $\left(\mathrm{Wm}^{-2}\right)$ & 315 & 315 & 0.02 & 311 & 301 & $<0.01$ \\
\hline Mean net shortwave $\left(\mathrm{kJ} \mathrm{m}^{-2}\right)$ & 72 & 52 & 0.01 & 19 & 17 & 0.35 \\
\hline Max net shortwave $\left(\mathrm{kJ} \mathrm{m}^{-2}\right)$ & 283 & 208 & 0.01 & 60 & 58 & 0.47 \\
\hline Mean incoming shortwave $\left(\mathrm{Wm}^{-2}\right)$ & 294 & 253 & 0.04 & 123 & 127 & 0.72 \\
\hline Mean energy balance $\left(\mathrm{kJ} \mathrm{m}^{-2}\right)$ & 16 & 2 & 0.01 & 2 & 1 & 0.12 \\
\hline Min energy balance $\left(\mathrm{kJ} \mathrm{m}^{-2}\right)$ & -36 & -79 & $<0.01$ & -16 & -17 & 0.31 \\
\hline Max energy balance $\left(\mathrm{kJm}^{-2}\right)$ & 172 & 84 & $<0.01$ & 20 & 17 & 0.22 \\
\hline$\Sigma 3 \mathrm{~d}$ energy balance positive $\left(\mathrm{kJ} \mathrm{m}^{-2}\right)$ & 4356 & 1959 & $<0.01$ & 671 & 493 & $<0.01$ \\
\hline$\Sigma 5 \mathrm{~d}$ energy balance positive $\left(\mathrm{kJ} \mathrm{m}^{-2}\right)$ & 6088 & 3840 & 0.14 & 1050 & 844 & 0.03 \\
\hline $\begin{array}{l}\text { Proportion zero cold } \\
\text { content at } 12: 00 \mathrm{~h}(\%)\end{array}$ & 91 & 85 & 0.04 & 91 & 78 & 0.02 \\
\hline $\begin{array}{l}\text { Max amount of total liquid water } \\
\text { within the snowpack }\left(\mathrm{kg} \mathrm{m}^{-2}\right)\end{array}$ & 23 & 9 & $<0.01$ & 0 & 0 & 0.6 \\
\hline
\end{tabular}

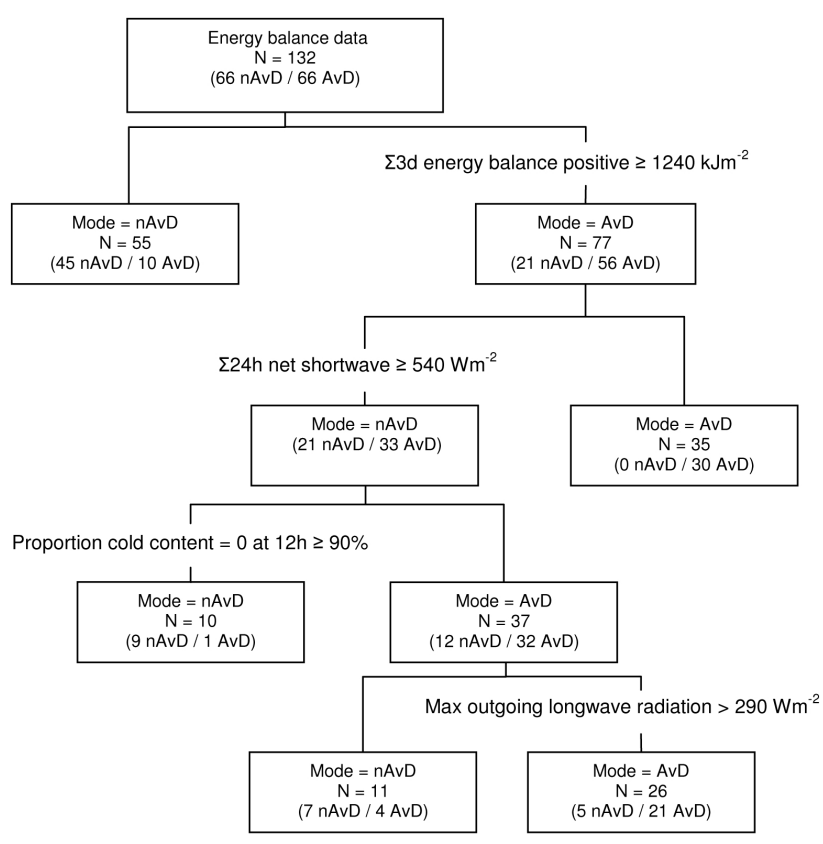

Fig. 4. Classification tree to discriminate between avalanche $(\mathrm{AAI}>2)$ and non-avalanche days. Input data were all energy balance variables calculated for a $35^{\circ}$ south-facing slope at $2500 \mathrm{~m}$ a.s.l. Forecast scores of the tree: probability of detection $(\mathrm{POD})=0.84$; probability of non-events $(\mathrm{PON})=0.83$; true skill score $(\mathrm{HK})=0.72$. the DFB data as the univariate analysis did not reveal enough variables $(N<7)$ that discriminated between the two groups of days. The model performance of the DFB tree was worse than the performance of the tree obtained with the WFJ data (Fig. 6). The DFB tree found the events with good accuracy, but produced more false alarms and scored low in detecting non-events.

For a south-facing slope at $2500 \mathrm{~m}$ a.s.1., the energy balance summed over 3 days split best followed by the mean net shortwave radiation using classification tree analysis (Fig. 4). The following nodes included the internal state of energy of the snowpack (zero cold content) and the maximum outgoing longwave radiation. For northern slopes (not shown here), again the sum of the energy balance over 3 days split best. The subsequent nodes included sensible heat and the mean of net longwave radiation. Results obtained with RandomForests are very similar to those from classification trees, but variable importance differed. The most important variable was the value of zero cold content at noon followed by the mean net shortwave radiation for southern aspects and the mean outgoing longwave radiation for northern aspects. Only then the sum of the positive energy balance values shows up for both aspects (Fig. 3a, b). Again the results obtained with the tree outperform the predictive skills of RF. In none of the multivariate approaches were variables related to the total amount of liquid water chosen.

In summary, for south-facing and north-facing slopes the energy balance over 3 days was the variable that split best between avalanche and non-avalanche days. The following 

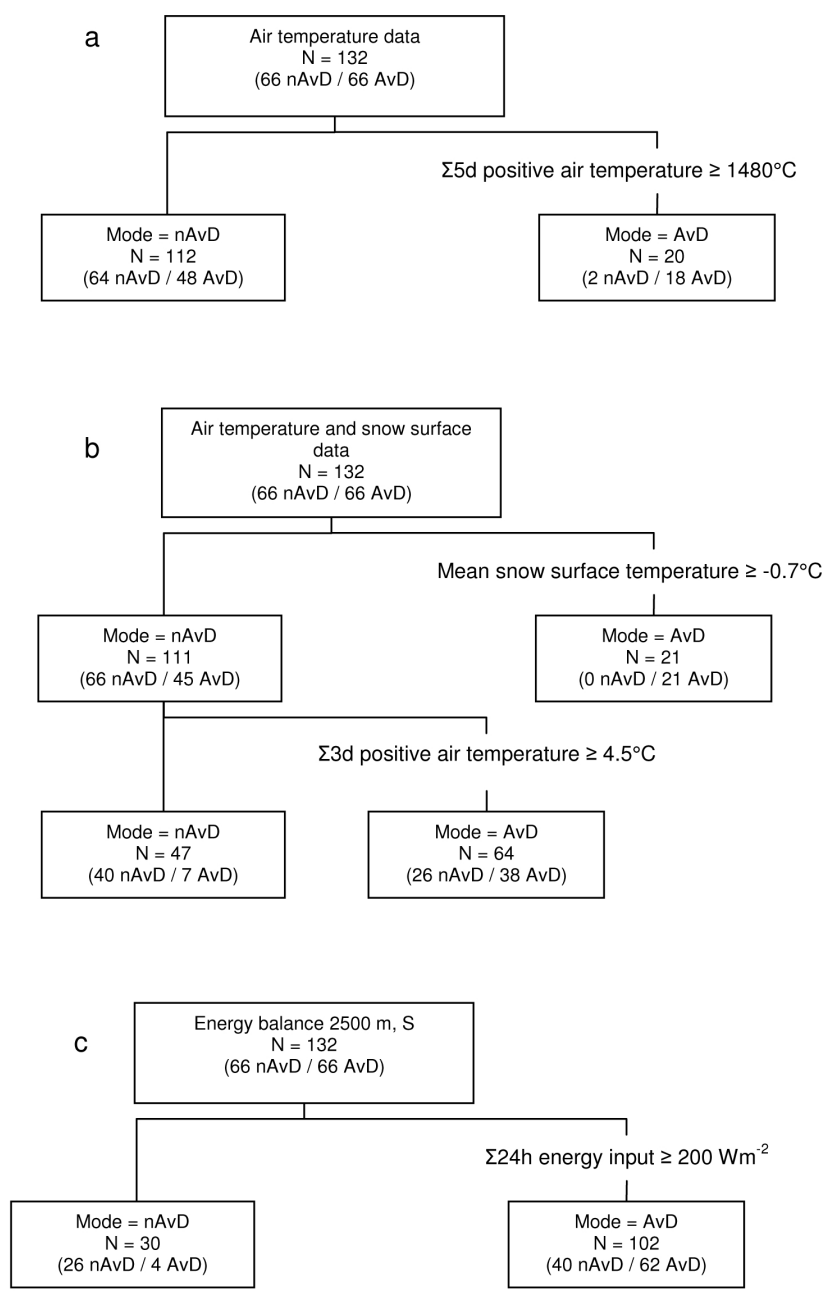

Fig. 5. (a) Classification tree for WFJ using air temperature information, (b) classification tree for air temperature and snow surface information and (c) for a virtual south-facing slope with energy balance information only (for predictive skills see Fig. 6).

splitting rules included incoming shortwave radiation and state of the internal energy for south-facing slopes and the sensible and net longwave radiation flux for north-facing slopes. For all cases the predictive skills of the trees were better than the ones of the RF analysis.

\subsection{Predictive skills of air temperature and energy balance}

So far results showed that the predictive skills of the two approaches with various input data sets were rather good and mostly agreed. In a next step, however, we wanted to know if either air temperature or the energy balance is sufficient for wet-snow avalanche forecasting and which of both performs better. When omitting the radiation terms in the tree presented in Fig. 2, the 5-day sum of positive air temperature remained as the only splitting parameter (Fig. 5a), but model

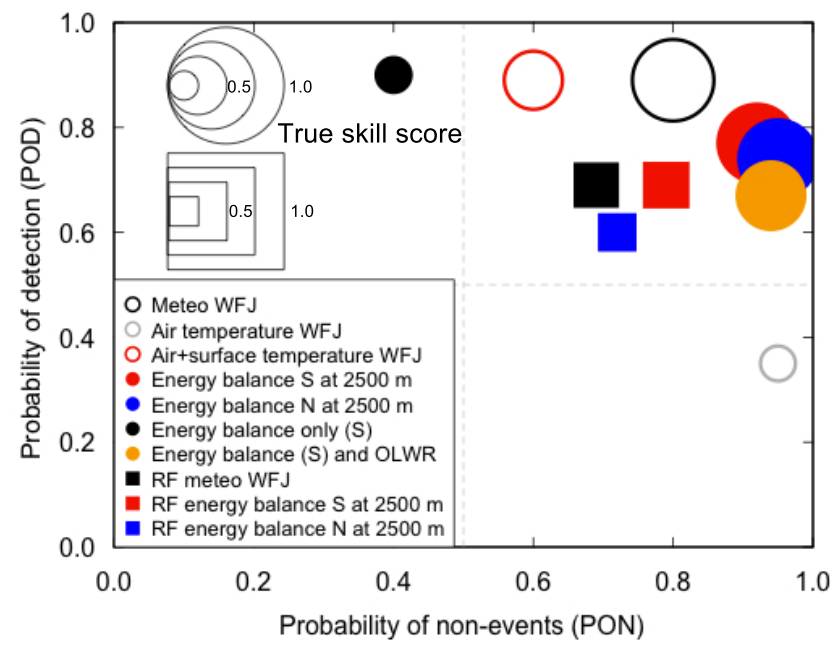

Fig. 6. Classification accuracy of different tree and RandomForest (RF) models for contrasting wet-snow avalanche days to nonavalanche days. Size of the symbols indicates the true skill score.

performance deteriorated (Fig. 6): the tree missed two thirds of all avalanche days, but hardly missed any non-event days. False alarms $(0.11)$ were fairly infrequent. When adding the snow surface temperature (Fig. $5 \mathrm{~b}$ ) the predictive power improved $(\mathrm{POD}=0.89, \mathrm{PON}=0.6, \mathrm{FAR}=0.3)$, but the prediction accuracy for the non-events went down and the falsealarm ratio increased. Nevertheless, the number of falsestable predictions was in the same range as with the more complex tree in Fig. 2. Using only information of the energy balance, the tree identified almost all events, but missed many non-events which means that almost two thirds of all non-avalanche days were classified as avalanche days. Introducing the outgoing longwave radiation (not shown here) increased the probability of non-events to $90 \%$, but decreased the probability to hit an avalanche day to $67 \%$ (Fig. 6).

\section{Discussion}

Compared to previous studies (e.g. Romig et al., 2005; Baggi and Schweizer, 2009; Peitzsch et al., 2012) the same meteorological variables showed discriminating power (e.g. air temperature), but also similar shortcomings in predictive skills. Our results suggest that no single variable representing the energy input is sufficient for forecasting wet-snow instability, unless combined with information on snow temperature and its evolution over time. Wet-snow avalanche activity was closely related to periods when large parts of the snowpack reached an isothermal state $\left(0^{\circ} \mathrm{C}\right)$ and energy input exceeded a maximum value of $200 \mathrm{~kJ} \mathrm{~m}^{-2}$ in one day (Table 4; Figs. 5 and 7), or the 3-day sum of positive energy input was larger than $1.2 \mathrm{MJ} \mathrm{m}^{-2}$ (Figs. 4 and 7). This combined information allows excluding days when the energy input is used for warming the snowpack and determining when surplus of 

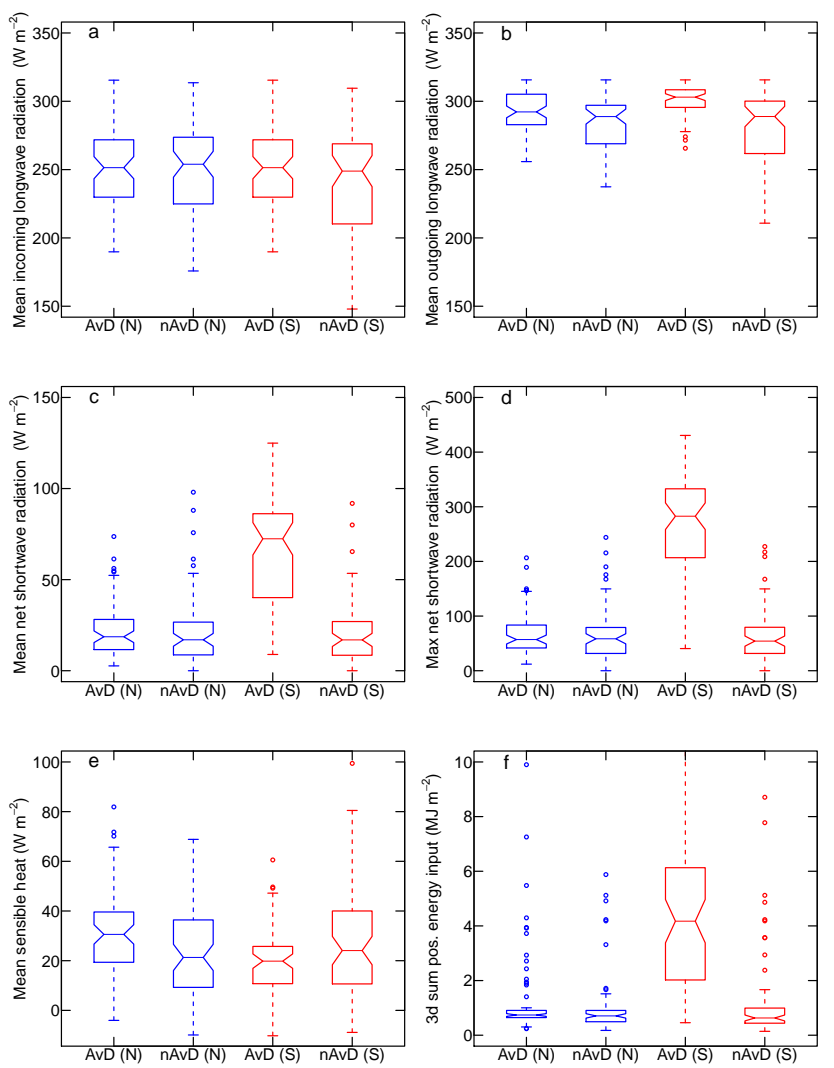

Fig. 7. Distribution of (a) mean incoming longwave radiation, (b) mean outgoing longwave radiation (c) mean net shortwave radiation, (d) max net shortwave radiation (e) mean sensible flux, and (f) the resulting 3-day sum of positive energy balance values for avalanche days (AvD) and non-avalanche days (nAvD) on southfacing (red) and north-facing (blue) slopes. Values were calculated with SNOWPACK assuming an elevation of $2500 \mathrm{~m}$ and a slope angle of $35^{\circ}$.

energy is used to melt snow, which helps to narrow down the onset of wet-snow avalanche activity. Some avalanche warning services, e.g. in New Zealand (Conway, 2005), take this fact into account by relating the convergence of snow temperature at different heights towards $0{ }^{\circ} \mathrm{C}$ to the start of a period with high probability of wet-snow avalanche release. Using simply the daily energy balance allowed detecting $90 \%$ of the wet-snow avalanche days; therefore, energy balance is superior to air temperature in detecting events. However, the problem is that many false alarms resulted, which is not satisfying and lowers the overall predictive skill. The true skill score $(\mathrm{HK})$ of the energy balance model was similar to the one of air temperature. Air temperature solely was not suited for predicting the events, but detected non-events fairly well. Combining air temperature with snow surface temperature improved predictive skills (Figs. 4 and 6). For practical applications, these two commonly measured parameters may be well suited, but can only describe flat field conditions.

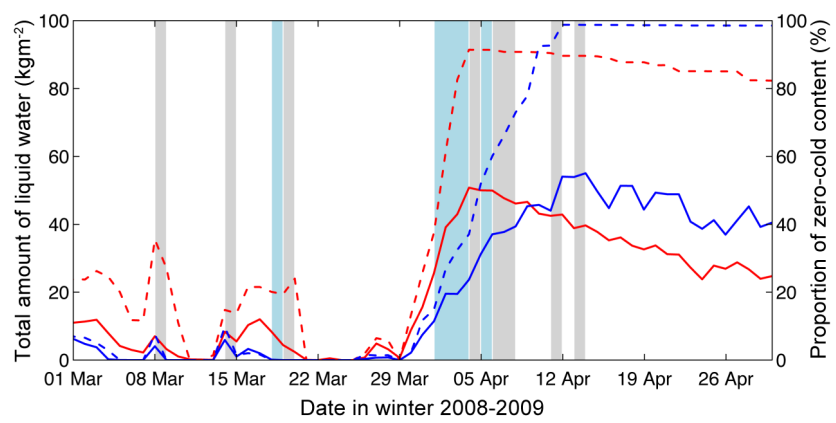

Fig. 8. Daily maximum amount of liquid water within the snowpack for a south-facing $35^{\circ}$ slope at $2200 \mathrm{~m}$ a.s.l. (red solid line) and $2500 \mathrm{~m}$ a.s.l. (blue solid line). Dashed lines show proportion of snowpack with a zero cold content ( $\mathrm{red}=2200 \mathrm{~m}$; blue $=2500 \mathrm{~m}$ ). The grey boxes indicate periods with wet-snow avalanche activity $(\mathrm{AAI}>2)$ recorded for the surroundings of Davos, Switzerland, blue boxes indicate major wet-snow avalanche cycles $(\mathrm{AAI}>30$, Table 1).

The total amount of liquid water was closely related to days with wet-snow avalanche occurrence on south-facing slopes (Fig. 1), but was generally a poor predictor. Prevailing high amounts of water production and equally a high proportion of zero cold content after the major avalanche cycle hamper the application of these variables for prediction (Fig. 8). In fact, none of the multivariate approaches used the total amount of water as a variable in its splitting rules. In contrast, the cold content was chosen as splitting rule in the multivariate approaches and seems to be more indicative for the onset of wet-snow instabilities. Previous work (Schweizer and Baggi, 2009) supports this fact.

Whether significant melt will affect stability depends not only on the meteorological forcing, but also on snowpack structure (Schneebeli, 2004; Baggi and Schweizer, 2009). Snow stratigraphy at the beginning of the melt season might be quite responsive to the addition of water, while more "mature" or ripe snowpack will not respond to the addition of water. As soon as the snowpack is ripe, an efficient drainage system will be established and water will no longer affect stability (Kattelmann, 1985). In situ measurements capturing the above described thermal and mechanical evolution are difficult to perform since changes tend to occur fast, and only represent point observations. Likewise, presently available simulated snow stratigraphy will not depict the complex feedback mechanisms of infiltrating water. On the other hand, avalanche activity tended to be widespread and occurred within a few days suggesting that the snow cover conditions were fairly uniform throughout the area for a certain aspect and elevation. This suggests that forcing by meteorological conditions was overriding local differences in snow stratigraphy and knowing the location and amount of liquid water within the snowpack is not always relevant.

Since most cycles in the periods we analysed occurred on slopes of southern aspect, it is not surprising that the net 
shortwave radiation provides most energy (Fig. 7). As single parameter it discriminated between event and non-event days for steep $\left(=35^{\circ}\right)$ southern aspects. Median values on avalanche days were about $80 \mathrm{~W} \mathrm{~m}^{-2}$, however, maximum values may be as high as $200-400 \mathrm{~W} \mathrm{~m}^{-2}$ within $60 \mathrm{~min}$ (Fig. 7). These maximum flux values might prevail only for $2-4 \mathrm{~h}$ per day, but cover around two thirds of the maximum energy input of a single day (Table 4). In case the snowpack is already at $0{ }^{\circ} \mathrm{C}$, this high energy input during a few hours will be directly transformed into $\sim 1.5 \mathrm{~mm}$ of water. On the other hand, the net longwave radiation was in general the largest negative component, i.e. energy loss (Fig. 7). Low negative net values hint to days with cloud cover or a melting snow surface. Cloud cover will attenuate the cooling effect at the snow surface, which will lead to high values for $L^{\uparrow}$. In fact, $L^{\uparrow}$ was in all statistical models a good splitter (Table 4 , Fig. 3).

The values of the turbulent heat fluxes $\left(H_{\mathrm{S}}\right.$ and $\left.H_{\mathrm{L}}\right)$ were in general lower than half the magnitude of the net irradiative fluxes, but especially $H_{\mathrm{S}}$ may on some days early in spring exceed the magnitude of the irradiative terms and therefore needs to be considered when calculating the energy input to the snowpack on a daily basis. It is, however, very difficult to reliably calculate $H_{\mathrm{S}}$ for complex terrain. The bulk method, which is used within SNOWPACK to calculate the turbulent fluxes, provides at best an estimate. It has, however, been shown that the method gives robust results for the location where the data were recorded (Plüss and Mazzoni, 1994). In order to obtain good results for the locations where the input needs to be extrapolated, air temperature, snow surface temperature and wind speed have to be representative. None of the three parameters can be verified for the slope simulations. Comparing the air temperature measured at the station Weissfluhjoch $(2540 \mathrm{~m}$ a.s.l.) to the one at the station Dorfberg suggests that the average lapse rate may be somewhat higher than the standard lapse rate of $0.65^{\circ} \mathrm{C} / 100 \mathrm{~m}$. To assess the underestimation we simulated $H_{\mathrm{S}}$ based on the data of the station DFB which revealed that the extrapolated value of $H_{\mathrm{S}}$ for $2200 \mathrm{~m}$ was on average $16 \%$ lower. On some days, however, $H_{\mathrm{S}}$ calculated with DFB was $20-30 \mathrm{Wm}^{-2}$ higher than with the time-lapse approach. Furthermore, the bulk method generally underestimates the sensible heat flux (Arck and Scherer, 2002). Nevertheless, we think that the difference between extrapolation and measurement is acceptable as we compare the meteorological conditions in a given elevation band to the avalanche activity on a regional scale - and not point by point. Our data included only one significant rain-on-snow event and the above-discussed results on energy balance terms may be biased to situations where irradiation and air temperature caused the melting.

Studying the melt of ice on glaciers is often based on temperature-index models assuming an empirical relationship between air temperature and melt rates. Ohmura (2001) has pointed out that air temperature is a reliable proxy for calculating the melt and that considering the full energy bal- ance does not substantially improve the results. This approach is debatable, but seems to work for glaciological studies (e.g. Braithwaite, 1995). One might therefore conclude that the same approach is applicable for predicting wet-snow avalanches as melt water is closely related to snowpack instability. However, temperature-index models have spatial and temporal deficiencies and rely heavily on the degree-day factor (DDF). The DDF may change with time due to changing albedo and with terrain properties (aspect, slope angle). de Quervain (1979) presented a 28-yr long series of DDF values calculated for the Weissfluhjoch test-site (flat) and concluded that a mean value of 4 can be applied for the entire melt period. The DDF values, however, scatter considerably and range from 2.7 to 6.1 depending on whether the melt process was dominated by radiation or air temperature. Radiation induced melting was underrepresented by the DDF. Furthermore, our wet-snow avalanches occurred in spring on steep terrain, so that terrain conditions would have to be considered (e.g. Hock, 2003). Whereas temperature-index models provide reasonable results for melt rates when integrated over long time periods, the accuracy decreases with increasing temporal resolution, which is a major disadvantage for wet-snow avalanche forecasting. Considering that the 5-day sum of positive air temperature missed most avalanche days (Fig. 5a), indicates that temperature-index models are not suited for our purpose.

Although our analyses are specific to the study area and so are some of the results, such as threshold values, many of the findings can be generalised. For example, for the prediction of the first large melt events, air temperature is not sufficient, but information at least on the thermal state of the snow cover is needed. Calculating energy input and cold content of the snowpack for a specific class of slopes and aspects will provide a good estimate for the first major melt - and hence of potential instability.

\section{Conclusions}

We compared $4 \mathrm{yr}$ of wet-snow avalanche occurrence in the surroundings of Davos, Switzerland to meteorological data measured by three automated weather stations and to simulated energy balance values. The energy balance was modelled for virtual slopes of southern and northern aspects using the 1-D snow cover model SNOWPACK.

Univariate analyses revealed that the distributions of air temperature, its positive sum over 3 or 5 days, the snow surface temperature, the 3-day sum of positive energy balance, the daily maximum amount of liquid water within the snowpack and the minimum value of the sensible flux were statistically different for wet-snow avalanche and non-avalanche days, suggesting that these variables have predictive power. Using only one explanatory variable revealed low scores in predicting days with high wet-snow avalanche activity. Too many false-alarms deteriorated the predictive power. 
Combining various variables in two different multivariate approaches provided satisfactory results. The model based on energy balance variables performed as well as the model using meteorological parameters, but better predicted nonevents. Modelling the energy balance for virtual slopes allows simulating the energy input, cold content and total amount of water for specific slopes and aspects. The resulting classification trees clearly demonstrate the importance of the energy input and proportion of cold content for forecasting wet-snow avalanches. For both, south-facing and northfacing slopes, the energy balance over 3 days was the variable that split best between avalanche and non-avalanche days.

In the presented approach, we focused on external drivers for melt production and did not consider the snowpack stratigraphy and its interaction with melt water. Despite this severe shortcoming, the results are promising for predicting wet-snow avalanche activity on a regional scale based on simulated variables using the snow cover model SNOWPACK. In the future, an approach combining more sophisticated water flux models and objective measurement devices, such as upward-looking radar systems, might help to improve prediction accuracy.

Acknowledgements. We would like to thank the editor Michiel van den Broeke, and the reviewers Howard Conway and Karl Birkeland who provided constructive comments that helped to improve the manuscript. C. M. was funded by the Swiss National Science Foundation (SNF, grant 200021-126889). We thank C. Fierz who helped to setup the SNOWPACK simulations and programmed the possibility to deduce the change in cold content within the software. For stimulating discussions we are grateful to F. Techel, B. Reuter, M. Schirmer and M. Lehning. We would like to thank the numerous observers who collected the avalanche occurrence data.

Edited by: M. Van den Broeke

\section{References}

Arck, M. and Scherer, D.: Problems in the determination of sensible heat flux over snow, Geogr. Ann. A, 84A, 157-169, 2002.

Baggi, S. and Schweizer, J.: Characteristics of wet snow avalanche activity: 20 years of observations from a high alpine valley (Dischma, Switzerland), Nat. Hazards, 50, 97-108, 2009.

Bhutiyani, M. R.: Field investigations on meltwater percolation and its effect on shear strength of wet snow, Proceedings Snow Symp - 94, Manali (H.P.), India, 200-206, 1996.

Braithwaite, R. J.: Positive degree-day factors for ablation on the Greenland ice-sheet studied by energy-balance modeling, J. Glaciol., 41, 153-160, 1995.

Breiman, L.: Random Forest, Mach. Learn., 45, 5-32, 2001.

Breiman, L., Friedman, J. H., Olshen, R. A., and Stone, C. J.: Classification and regression trees, CRC Press, Boca Raton, USA., 368 pp., 1998.
Brun, E. and Rey, C.: Field study on snow mechanical properties with special regard to liquid water content, IAHS-AISH P., 162, 183-193, 1987.

Conway, H.: Storm Lewis: a rain-on-snow event on the Milford Road, New Zealand, Proceedings ISSW 2004, International Snow Science Workshop, Jackson Hole WY, USA., 19-24 September 2004, 557-564, 2005.

de Quervain, M.: Schneedeckenablation und Gradtage im Versuchsfeld Weissfluhjoch, Mitteilung Nr. 41 der Versuchsanstalt für Wasserbau, Hydrologie und Glaziologie an der ETH Zürich, 215-232, 1979.

Doswell, A., Davies-Jones, R., and Keller, D.: On summary measures of skill in rare event forecasting based on contingency tables, Weather and Forecast., 5, 576-585, 1990.

Fierz, C. and Föhn, P. M. B.: Long-term observation of the water content of an alpine snowpack, Proceedings International Snow Science Workshop, Snowbird, Utah, USA, 30 October-3 November 1994, 117-131, 1995.

Hirashima, H., Nishimura, K., Yamaguchi, S., Sato, A., and Lehning, M.: Numerical modeling of liquid water movement through layered snow based on new measurements of the water retention curve, Cold Reg. Sci. Technol., 64, 94-103, 2010.

Hock, R.: Temperature index melt modelling in mountain areas, J. Hydrol., 282, 104-115, 2003.

Kattelmann, R.: Wet slab instability, Proceedings International Snow Science Workshop, Aspen, Colorado, USA, 24-27 October 1984, 102-108, 1985.

King, J. C., Pomeroy, J., Gray, D. M., Fierz, C., Föhn, P., Harding, R. J., Jordan, R., Martin, E., and Plüss, C.: Snow-atmposphere energy mass balance, in: Snow and Climate, edited by: Armstrong, R., and Brun, E., Cambridge, 70-124, 2008.

Lehning, M. and Fierz, C.: Assessment of snow transport in avalanche terrain, Cold Reg. Sci. Technol., 51, 240-252, 2008.

Lehning, M., Bartelt, P., Brown, R. L., and Fierz, C.: A physical SNOWPACK model for the Swiss avalanche warning; Part III: meteorological forcing, thin layer formation and evaluation, Cold Reg. Sci. Technol., 35, 169-184, 2002a.

Lehning, M., Bartelt, P., Brown, R. L., Fierz, C., and Satyawali, P. K.: A physical SNOWPACK model for the Swiss avalanche warning; Part II. Snow microstructure, Cold Reg. Sci. Technol., 35, 147-167, 2002b.

Marty, C.: Surface radiation, cloud forcing and greenhous effect in the Alps, Zürcher Klima-Schriften, Institut für Klimaforschung ETH, Zürich, Switzerland, 79, 122, doi:10.3929/ethz-a003897100, 2001.

McClung, D. M. and Schaerer, P.: The Avalanche Handbook, 3rd Edn., The Mountaineers Books, Seattle WA, USA, 342 pp., 2006.

Mitterer, C., Hirashima, H., and Schweizer, J.: Wet-snow instabilities: Comparison of measured and modelled liquid water content and snow stratigraphy, Ann. Glaciol., 52, 201-208, 2011.

Ohmura, A.: Physical basis for the temperature-based melt-index method, J. Appl. Meteorol., 40, 753-761, 2001.

Peitzsch, E. H., Hendrikx, J., Fagre, D. B., and Reardon, B.: Examining spring wet slab and glide avalanche occurrence along the Going-to-the-Sun Road corridor, Glacier National Park, Montana, USA, Cold Reg. Sci. Technol., 78, 73-81, 2012.

Plüss, C. and Mazzoni, R.: The role of turbulent heat fluxes in energy balance of high alpine snow cover, Nord. Hydrol., 25, 25$38,1994$. 
Romig, J. M., Custer, S. G., Birkeland, K. W., and Locke, W. W.: March wet avalanche prediction at Bridger Bowl Ski Area, Montana, Proceedings ISSW 2004, International Snow Science Workshop, Jackson Hole WY, USA., 19-24 September 2004, 598-607, 2005.

Schneebeli, M.: Mechanisms in wet snow avalanche release, Proceedings ISSMA-2004, International Symposium on Snow Monitoring and Avalanches, Manali, India, 12-16 April 2004, 75-77, 2004.

Schweizer, J., Jamieson, J. B., and Schneebeli, M.: Snow avalanche formation, Rev. Geophys., 41, 1016, doi:10.1029/2002RG000123, 2003a.

Schweizer, J., Kronholm, K., and Wiesinger, T.: Verification of regional snowpack stability and avalanche danger, Cold Reg. Sci. Technol., 37, 277-288, 2003b.

Schweizer, J., Mitterer, C., and Stoffel, L.: On forecasting large and infrequent snow avalanches. Cold Reg. Sci. Technol., 59, 234 241, 2009

Spiegel, M. R. and Stephens, L. J.: Schaum's outline of theory and problems of statistics, 3rd Edn., Schaum's outline series, McGraw-Hill, New York, 538 pp., 1999.

Stössel, F., Guala, M., Fierz, C., Manes, C., and Lehning, M.: Micrometeorological and morphological observations of surface hoar dynamics on a mountain snow cover, Water Resour. Res., 46, W04511, doi:10.1029/2009WR008198, 2010.
Techel, F. and Pielmeier, C.: Wet snow diurnal evolution and stability assessment, Proceedings ISSW 2009, International Snow Science Workshop, Davos, Switzerland, 27 September-2 October 2009, 256-261, 2009.

Techel, F. and Pielmeier, C.: Snowpack properties of unstable wet snow slopes: observations from the Swiss Alps, Proceedings ISSW 2010, International Snow Science Workshop, Lake Tahoe, California, USA, 17-22 October 2010, 187-193, 2010.

Techel, F. and Pielmeier, C.: Point observations of liquid water content in wet snow - investigating methodical, spatial and temporal aspects, The Cryosphere, 5, 405-418, doi:10.5194/tc-5-4052011, 2011.

Trautman, S.: Investigations into wet snow, The Avalanche Review, 26, 16-17, 2008.

Wilks, D. S.: Statistical methods in the atmospheric sciences: an introduction, International Geophysics, Academic Press, San Diego CA, USA, 467 pp., 1995.

Yamanoi, K. and Endo, Y.: Dependence of shear strength of snow cover on density and water content, Seppyo J. Jpn. Soc. Snow Ice, 64, 443-451, 2002.

Zwimpfer, F.: Failure of wet snow, BSc Thesis, Swiss Federal Institute of Technology, Zurich, 45 pp., 2011. 